\title{
Comparison of the Lower Trapezius Muscle Activity during Three Different Shoulder Flexion Exercises in Healthy Subjects
}

\author{
Byeong-Hun Hwang, Tae-Jin Jang, In-Cheol Jeon \\ Department of Physical Therapy, College of Life and Health Science, Smart Healthcare Convergence Research Center, Hoseo University, Asan, \\ Republic of Korea
}

Purpose: This study investigated the muscle activity of the lower trapezius (LT) during three different shoulder flexion exercises.

Methods: Twenty-three subjects between 20 and 25 years of age were enrolled. The subjects were asked to perform three different shoulder flexion exercises: 1) shoulder flexion in prone (SFP), 2) shoulder flexion in push-up with a swiss ball (SFPUS) and 3) shoulder flexion in a quadruped position with a swiss ball (SFQPS) in random order. The muscle activity of LT during each shoulder flexion exercise was measured by using surface electromyography. The muscle activity of LT was compared using one-way analysis of variance (ANOVA) and Bonferroni post hoc test among three different shoulder flexion exercises. The statistical significance level was set at $\alpha=0.01$.

Results: The muscle activity of LT was significantly different among three different shoulder flexion exercises (SFP, SFPUS, and SFOPS). The LT muscle activity with SFOPS exercise was greater than SFP and SFPUS exercises $(p<0.01)$. There was no significant difference in LT muscle activity between SFP and SFPUS exercises ( $p>0.01$ ).

Conclusion: The LT muscle activity was greater during SFQPS than SFP and SFPUS. Therefore, SFQPS exercise can be recommended for selectively activation of LT muscle.

Keywords: Base of support, Lower trapezius, Shoulder flexion, Muscle activation

\section{서 론}

지지면(base of support, BOS)은 물체 또는 사람이 지지하는 표면과 만 드는 접촉범위를 말하며, 몸을 지지하고 있는 면을 의미한다. 이러한 접촉범위는 신체의 손과 발 또는 목발이나 사람이 앉아 있는 의자와 같은 물체가 형성하고 있는 공간이 포함된다. 지지면은 열린 사슬 또 는 닫힌 사슬 운동 시 고려되는데, 지지면의 크기와 형태를 변화시켜 서 운동을 수행하면 해당근육의 활성도와 근수축 개시시간(muscle onset time) 등에 영향을 미치기 때문에 선행연구들이 많이 진행되어 왔다.2,3 불안정한 지면(unstable base of support)에 체중을 지지하면 관 절을 안정화하기 위해 더 많은 근육 활성화와 관절의 고유수용성감 각이 촉진된다. 선행연구에 따르면 스위스볼(swiss ball) 위에 손을 올 리고 푸쉬업(push up)운동을 수행했을 때 위팔세갈래근, 배곧은근, 배바깥빗근의 근활성도가 증가했으며, ${ }^{2}$ 어깨관절 뒤쪽 탈구가 있는 대상자가 워블보드(wobble board)를 이용한 운동을 수행했을 때 어 깨관절의 안정성과 근력이 증가하였다. ${ }^{3}$ 이처럼 불안정한 지면에서의
운동은 해당 관절에서 운동 손상의 관리와 수행능력 향상을 위해 사 용된다.

등세모근은 해부학적으로 위, 중간, 아래로 나뉜다. 그 중 아래등세 모근의 주된 기능은 어깨뼈 내림(scapular depression), 모음(adduction), 돌림(rotation) 그리고 등 척추의 폄을 수행한다. ${ }^{4}$ 아래등세모근의 활 성화는 관절오목에 대하여 위팔뼈의 축 돌림을 안정화하고, ${ }^{5}$ 어깨뼈 의 뒤쪽 기울임에 기여한다. 이런 운동학적 요소는 팔을 들어 올리는 동작 시 앞쪽 어깨봉우리와 돌림근띠(rotator cuff) 힘줄 사이가 좁아 지는 것을 최소화하기 때문에, ${ }^{6}$ 적절한 자세 정렬 유지와 오목위팔관 절 기능에 중요한 근육이다. 하지만, 선행연구에 따르면 이 근육은 적 절한 근육신경계 재교육과 충분한 근력을 훈련하는 것이 비교적 어 려운 근육 중 하나이며, 근육 비대칭의 신경생리학적 반응과 돌기사 이관절의 기능 이상이 근육 약화를 야기시키는 것으로 보고되었다. ${ }^{8}$ 아래등세모근의 약화로 인한 위등세모근과의 근육 불균형(muscle imbalance)은 비정상적인 어깨뼈 움직임과 어깨 밑 충돌증후군(subacromial impingement), 돌림근띠, 위팔두갈래근(biceps brachii) 힘줄
Received Jan 11, 2022 Revised Jan 26, 2022

Accepted Jan 28, 2022

Corresponding author In-Cheol Jeon

E-mail jeon6984@hoseo.edu
Copylight (C2022 The Korean Society of Physical Therapy

This is an Open Access article distribute under the terms of the Creative Commons Attribution Non-commercial License (https:// creativecommons.org/license/by-nc/4.o.) which permits unrestricted non-commercial use, distribution, and reproduction in any medium, provided the original work is properly cited. 
염(tendonitis)의 원인이 된다.8,

아래등세모근을 포함하는 어깨뼈 주변 근육들은 운동학적으로 중요한 요소이다..$^{10}$ 선행연구에서는 건강한 대상자들의 아래등세모 근 근활성도를 비교하기 위해 앉은 자세에서 밀어 올리기 운동(seated press up)과 세라밴드(thera-band)를 이용한 열린 사슬 운동을 수행하 였다. ${ }^{11}$ 이 연구의 결과는 앉은 자세에서 밀어 올리기 운동이 위등세 모근, 중간등세모근과 비교했을 때 아래등세모근의 \%MVIC (percentage maximum voluntary isometric contraction)가 유의미하게 증가 했으며, 세라밴드를 이용한 어깨관절 가쪽돌림운동은 아래등세모근 이 위등세모근보다 높은 근활성도를 보였다. ${ }^{11}$ 다른 선행연구에서는 다양한 운동(엎드린 자세에서 아래등세모근 근섬유 방향에 맞춰 팔 을 벌림 한 상태로 팔을 들어 올리기 운동, 어깨면[plane of scapula] $120^{\circ}$ 이상의 각도에서 벌림 운동, 어깨면 $80^{\circ}$ 이하의 각도에서 벌림 운 동 등)에서의 아래등세모근 근활성도를 조사하였는데, 엎드린 자세 에서 아래등세모근 근섬유 방향에 맞춰 팔을 벌림 한 상태로 팔을 들 어 올리기 운동이 가장 높은 \%MVIC 값을 보였다. ${ }^{2}$ 이처럼 어깨 굽힘 또는 벌림 각도 그리고 다양한 환경에서 아래등세모근의 근활성도 연구가 이뤄지고 있다.

어깨관절은 신체에서 가장 움직임이 자유로운 관절 중 하나이다. 그 중 어깨 굽힘 동작은, 머리 위로 물건을 들어 올리거나, 물건을 잡 기 위해 팔을 뻗기(reaching)와 같은 일상적 기능뿐만 아니라, 동적인 스포츠 활동과 업무환경에서도 빈번히 나타나는 동작이다. 동적인 어깨 굽힘 수행 시 큰가슴근과 앞어깨세모근의 근활성도가 비슷하 게 나타났으며, 아래등세모근, 위등세모근, 앞톱니근의 근활성도 또 한 비슷한 수치를 보였다. ${ }^{13}$ 어깨 굽힘을 유발하는 근육들의 동원패 턴(recruitment pattern)은 대부분 유사하였고, 이는 완전관절가동범 위(full range of motion)를 수행하기 위한 위팔뼈와 어깨뼈 사이의 조 화를 나타낸다..$^{13}$ 이처럼 어깨 굽힘 완전관절가동범위는 다양한 근육 들의 작용과 여러 관절들의 기능이 결합되어 만들어진 복합적인 움 직임이다.

최적의 아래등세모근 근활성도를 확인한 선행연구에 따르면, 위팔 뼈가 $90^{\circ}$ 와 $150^{\circ}$ 사이 벌림 된 상태에서 로잉(rowing)을 수행했을 때 아 래등세모근이 가장 활성화되었다. ${ }^{14}$ 또한, 위팔뼈 벌림이 어깨면 $90^{\circ}$ 와 120 사이에서 수행되었을 때 아래등세모근의 근활성도가 가장 효 율적이었다는 연구도 있었다. ${ }^{15}$ 어깨관절 벌림 각도 $\left(75^{\circ}, 90^{\circ}, 125^{\circ}, 160^{\circ}\right.$ $180^{\circ}$ )에 따른 아래등세모근의 근활성도를 비교한 연구에서는 어깨관 절 벌림 $160^{\circ}$ 가 수행된 상태에서 팔을 들어 올렸을 때 가장 높은 아래 등세모근 근활성도를 보였다. ${ }^{16}$ 이처럼 아래등세모근을 효율적으로 활성화시키는 운동 방법은 위팔뼈를 벌림 또는 굽힘 하는 상태에서 실시하는 것이며, 이를 Y자-운동(Y-exercise)이라고 한다. 하지만 어깨 굽힘 운동 동안 지지면의 크기와 형태에 변화를 주어 아래등세모근
의 근활성도를 비교한 연구는 없었다.

이 연구의 목적은 지지면을 변화시킨 세 가지 다른 어깨 굽힘 운동 1) 엎드린 자세에서 어깨 굽힘 운동(shoulder flexion in prone, SFP), 2) 스위스볼 위에서 푸쉬업 자세로 어깨 굽힘 운동(shoulder flexion in push-up with swiss ball, SFPUS), 3) 스위스볼 위에서 네발기기 자세로 어깨 굽힘 운동(shoulder flexion in quadruped position with swiss ball, SFQPS) 동안의 아래등세모근 근활성도가 가장 증가되는 운동을 확 인하는 것이다. 따라서 본 연구의 가설은 네발기기 자세로 지지면을 작게 형성하고 불안정한 지면을 추가한 SFQPS운동이 SFP, SFPUS운 동보다 아래등세모근의 근활성도가 유의하게 증가할 것으로 설정하 였다.

\section{연구 방법}

\section{1. 연구대상}

20 대 건강한 성인 남성 23 명 $(23.5 \pm 1.2$ years, $174 \pm 6.3 \mathrm{~cm}, 76.2 \pm 13.2 \mathrm{~kg})$ 이 본 연구에 참여하였다. 선정기준은 1) 상지에 관련된 수술 이력이 없는 자, 2) 지난 6 개월 이내 어깨관절손상을 받지 않은 자, 3) 어깨관 절 통증으로 인한 움직임 제한이 없는 자, 4) 신경계 질환과 어깨관절 구축이 없는 자, 5) 상지에 염증 증상이 없는 자로 설정하였다. 모든 대 상자들은 실험 전, 자발적 참여 동의서에 서명 후 실험에 참여하였다. 본 연구는 연구기관 생명윤리심의위원회의 승인을 받고 진행하였다.

\section{2. 측정도구 및 방법}

근활성도 측정을 위해 EMG-feedback (wireless EMG System 1,000, BTS, Italy)을 사용하였으며, 전용 소프트웨어를 통해 분석하였다. 근 전도 신호는 대역 통과 필터 $(20-450 \mathrm{~Hz})$, 표본추출률 $(1,024 \mathrm{~Hz})$, 여과 필터 $(60 \mathrm{~Hz})$ 로 설정하였으며, root-mean-square (RMS) data와 a moving window $50 \mathrm{~ms}$ 처리되었다. 대상자가 세 가지 다른 어깨 굽힘 운동을 수행할 때 지지면의 변화를 주기 위해 견고하고 높이 조절이 가능한 테이블과, 스위스볼(swiss ball)을 사용하였다. 대상자들이 세 가지 운 동을 수행할 때 운동의 끝 지점에서 어깨관절 굽힘 각도가 $180^{\circ}$ 임을 확인하기 위해 각도기(goniometer)를 사용하였으며, 대상자가 팔을 들어 올리는 높이는 타겟바(target bar)를 사용하여 통제하였다. 근전 도 신호는 대상자가 등척성 어깨 굽힘을 유지한 상태에서 5 초 동안 기록하였다. 근전도 신호의 초기 1 초와 끝 1 초는 제거하였다. ${ }^{1718}$ 근전 도 전극이 부착되는 피부 위를 알코올 솜으로 세척하여 피부 저항을 최소화하였다. 어깨를 $90^{\circ}$ 굽힌 상태에서 어깨뼈 가시뿌리 $5 \mathrm{~cm}$ 아래 안쪽 위치에 일회용 $\mathrm{Ag} / \mathrm{AgCl}$ 표면 전극을 수직선에 비스듬하게 위, 아래로 부착하였다. ${ }^{19}$ 각 전극 사이는 $2 \mathrm{~cm}$ 거리를 두었다. 근력을 표 준화하기 위해 아래등세모근의 maximum voluntary isometric con- 
traction (MVIC)를 이용하여 표준화를 진행하였다. 엎드린 상태에서 팔을 $130^{\circ}$ 벌린 후 팔을 올리는 방향에 반대쪽으로 최대의 저항을 주 어 아래등세모근의 MVIC값을 산출하였다. 아래등세모근의 최대근 수축 수행을 3 회 측정하여 MVIC의 평균값으로 계산하였다. 근전도 신호를 이용하여 세 가지 다른 어깨 굽힘 운동(SFP, SFPUS, SFQPS)의 $\% \mathrm{MVIC}$ 로 계산하여 표기하였다. 운동을 수행할 때 근피로를 최소화 하기 위해 동작 사이에 2분씩 휴식을 가졌고, 측정 전 2-3회 연습을 실시하였다. 대상자들이 운동의 효과를 모르도록 하였고, 운동순서 는 무작위화하였다.

\section{3. 실험절차}

\section{1) Shoulder flexion in prone (SFP)}

대상자를 견고하고 높이 조절이 가능한 테이블 위에 곧게 엎드리게 한 뒤, 양 팔을 $120^{\circ}$ 로 벌린 자세를 취하게 하고, 팔을 들어 올리는 높 이가 운동의 끝 지점에서 어깨 굽힘 $180^{\circ}$ 가 수행되도록 타겟바의 높 이를 수정하였다. 해부학적 구조로 인한 제한이 발생하는 것을 방지 하기 위해 위팔뼈를 가쪽 돌림 시키고 손바닥은 천장을 향하게 하였 다..$^{20}$ 어깨 굽힘 $180^{\circ}$ 에서 최대 굽힘 근력이 유지된 채로 5 초 동안 아래 등세모근의 근활성도를 측정하였다. 5 초 뒤에는 서서히 원래 자세로 돌아오도록 하였다(Figure 1).

\section{2) Shoulder flexion in push-up with swiss ball (SFPUS)}

푸쉬업 자세에서 스위스볼을 대상자의 복장뼈 높이에 맞추어 위치 시켰다. 대상자는 스위스볼 위에서 양 팔을 $120^{\circ}$ 로 벌린 자세를 취하 였다. 팔을 들어 올리는 높이가 운동의 끝 지점에서 어깨 굽힘 $180^{\circ}$ 가 수행되도록 타겟바의 높이를 수정하였다. 해부학적 구조로 인한 제 한이 발생하는 것을 방지하기 위해 위팔뼈를 가쪽 돌림 시키고 손바 닥은 천장을 향하게 하였다. ${ }^{20}$ 어깨 굽힘 $180^{\circ}$ 에서 최대 굽힘 근력이 유지된 채로 5 초 동안 아래등세모근의 근활성도를 측정하였다. 5 초 뒤에는 서서히 원래 자세로 돌아오도록 하였다(Figure 1).
3) Shoulder flexion in quadruped position with swiss ball (SFQPS) 네발기기자세에서 스위스볼을 대상자의 복장뼈 높이에 맞추어 위치 시켰다. 대상자는 스위스볼 위에서 양 팔을 $120^{\circ}$ 로 벌린 자세를 취하 였다. 팔을 들어 올리는 높이가 운동의 끝 지점에서 어깨 굽힘 $180^{\circ}$ 가 수행되도록 타겟바의 높이를 수정하였다. 해부학적 구조로 인한 제 한이 발생하는 것을 방지하기 위해 위팔뼈를 가쪽 돌림 시키고 손바 닥은 천장을 향하게 하였다. ${ }^{20}$ 어깨 굽힘 $180^{\circ}$ 에서 최대 굽힘 근력이 유지된 채로 5 초 동안 아래등세모근의 근활성도를 측정하였다. 5 초 뒤에는 서서히 원래 자세로 돌아오도록 하였다(Figure 1).

\section{4. 자료분석}

본 연구에서 측정된 데이터는 SPSS software (ver. 18.0, SPSS IL, Chicago)를 통해서 분석하였다. 측정 데이터의 정규성 검정을 위해 Kolmogorov-Smirnov test를 사용하였고, 데이터는 정규분포하였다. 세 가 지 다른 어깨 굽힘 운동 동안 아래등세모근의 근활성도를 알아보기 위해 일원배치분산분석(One-way ANOVA)을 사용하였다. 운동 간 사 후검정를 위해 Bonferroni adjustment를 통해서 분석하였다(Figure 2). 유의수준은 $\alpha=0.01$ 로 설정하였다.

\section{결 과}

세 가지 다른 어깨 굽힘 운동에서 아래등세모근 근활성도의 유의한 차이를 확인할 수 있었다 $(\mathrm{p}<0.01)$. 아래등세모근의 근활성도는 SFQPS운동이 SFP, SFPUS운동보다 유의미하게 증가하였다 $(\mathrm{p}<0.01)$. 반면 SFP운동과 SFPUS운동 사이의 아래등세모근 근활성도는 차이 가 없었다( $\mathrm{p}>0.01)$ (Table 1, Figure 3).

\section{고 찰}

아래등세모근의 근활성도는 SFP, SFPUS운동보다 SFQPS운동에서 유
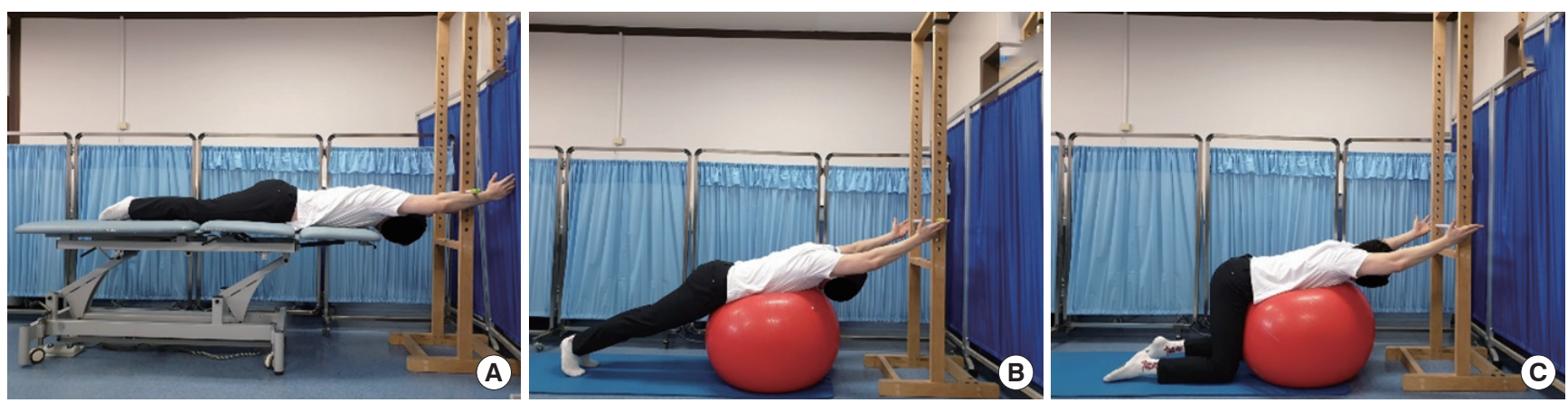

Figure 1. Three different shoulder flexion exercises. (A) Shoulder flexion in prone, (B) Shoulder flexion in push-up with swiss ball, (C) Shoulder flexion in quadruped position with swiss ball. 


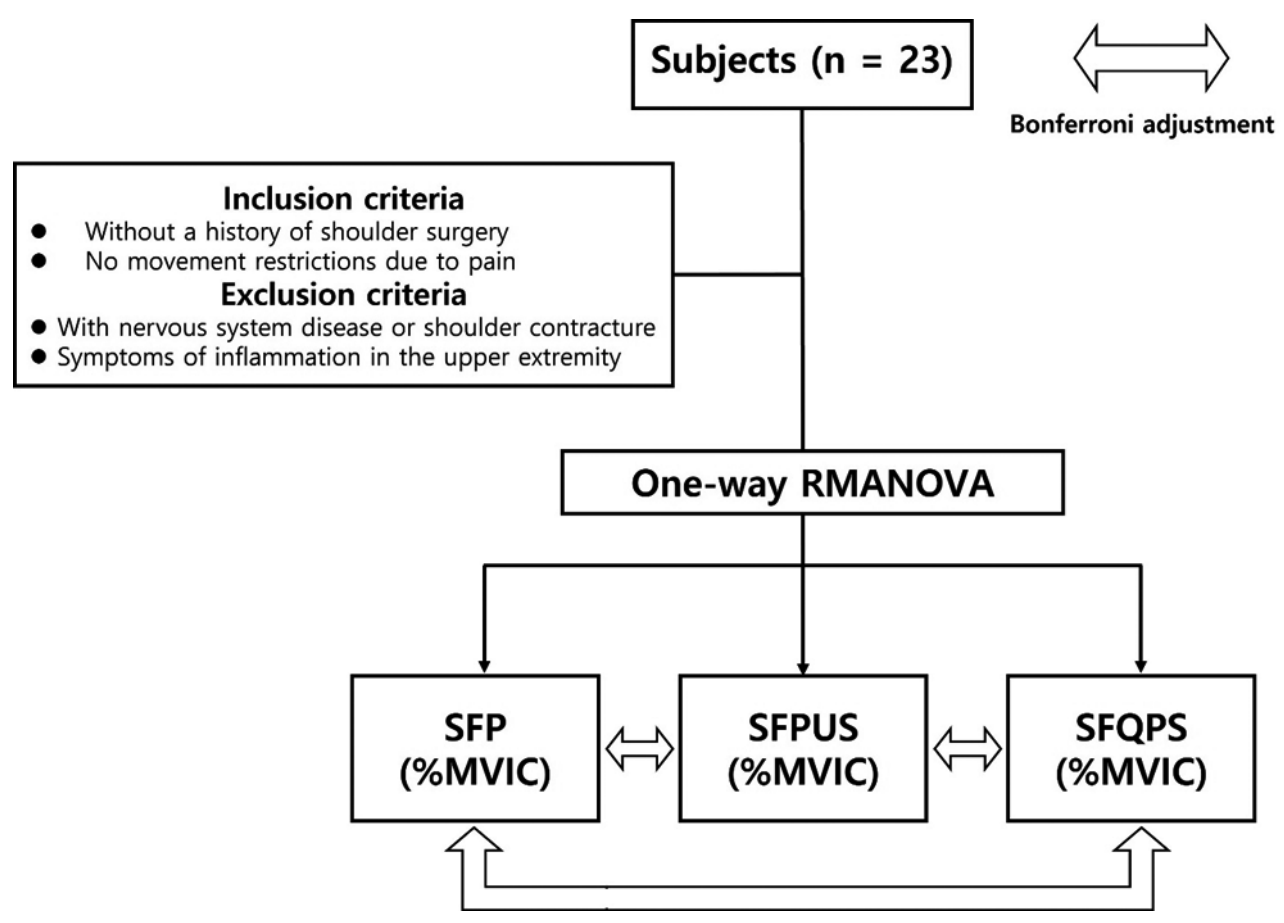

Figure 2. Flow chart.

Table 1.\%MVIC analysis

\begin{tabular}{lccccc}
\hline \multirow{2}{*}{ Muscle } & \multicolumn{3}{c}{ Mean \pm SD $(\% M V I C)$} & \multirow{2}{*}{ Fvalue } & p value \\
\cline { 2 - 4 } & SFP & SFPUS & SFQPS & & \\
\hline LT & $61.32 \pm 14.12$ & $69.44 \pm 12.92$ & $78.98 \pm 9.29$ & 11.3 & $<0.01^{*}$
\end{tabular}

SFP: shoulder flexion in prone, SFPUS: shoulder flexion in push-up with swiss ball, SFQPS: shoulder flexion in quadruped position with swiss ball, LT: lower trapezius, SD: standard deviation, MVIC: maximum voluntary isometric contraction, *significant differences.

의한 증가를 보였다. SFQPS운동이 SFP운동과 비교하여 아래등세모 근의 근활성도가 약 $22 \%$ 증가하였고, SFPUS운동과 비교하여 약 $12 \%$ 증가하였다. 본 연구의 목적은 세 가지 다른 어깨 굽힘 운동(SFP, SFPUS, SFQPS)에서의 아래등세모근의 근활성도를 비교하는 것이며, 이 때 SFQPS운동에서 아래등세모근의 근활성도가 다른 운동보다 더 높을 것이라는 가설을 세웠다.

위와 같은 결과가 나온 이유는, 첫 번째 지지면의 크기 변화가 아래 등세모근의 근활성도에 영향을 미친 것이라 볼 수 있다. 본 연구에서 수행된 세 가지 다른 어깨 굽힘 운동의 지지면 크기를 비교했을 때 SFP운동은 테이블 위에 엎드린 자세에서 동작을 수행했기 때문에 지 지면의 크기가 가장 크다. 따라서 안정적인 환경에서 어깨 굽힘이 수 행되었기 때문에 아래등세모근 근활성도 증가에 큰 영향을 미치지 못했다. SFPUS운동의 경우 푸쉬업 자세에서 스위스볼을 복장뼈 높 이에 위치시킨 상태로 어깨 굽힘 운동을 수행했기 때문에 지지면의 크기는 발끝에서부터 스위스볼의 면적까지 형성된 것으로 사료된다 이러한 요소가 SFP운동과 비교하여 좀 더 좁은 지지면을 형성했기

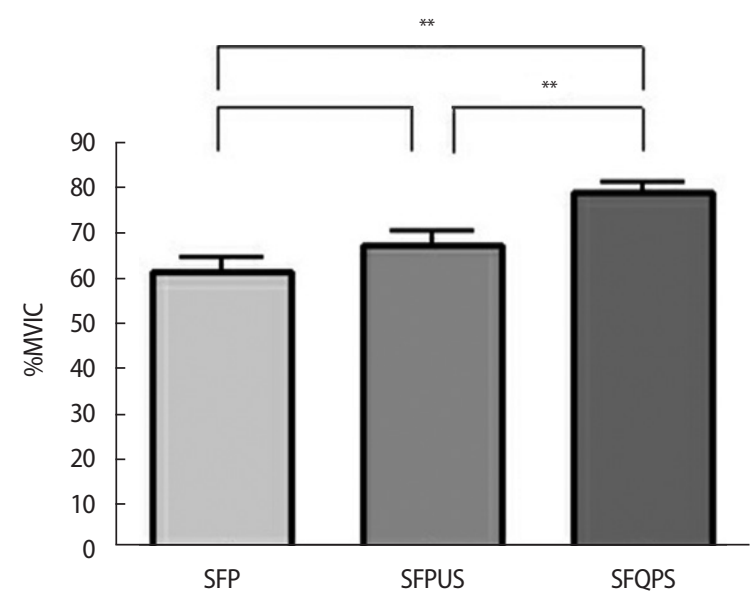

Figure 3. Change of muscle activities among exercises.

때문에 어깨 굽힘 운동을 수행하면서 아래등세모근의 근활성도 증 가에 기여한 것으로 보여진다. SFQPS운동의 경우 네발기기자세에서 스위스볼을 복장뼈 높이에 위치시켜 어깨 굽힘 운동을 수행했기 때 문에 형성되는 지지면은 무릎에서부터 스위스볼의 면적까지 형성된 것으로 사료된다. 따라서 SFPUS운동과 비교하여 SFQPS운동에서 형 성된 지지면이 더 좁기 때문에 어깨 굽힘을 수행했을 때 아래등세모 근 근활성도 증가에 가장 크게 기여한 것으로 생각된다. 본 연구의 결 과는 유사하게 진행된 선행연구와 다른 결과를 보였다. ${ }^{21}$ 선행연구에 서는 standard knee push up plus (KPP)운동과 one-handed KPP운동 수 행 시 아래등세모근의 근활성도에 유의한 차이가 없다는 결과를 발 
표하였다. ${ }^{21}$ 이처럼 다른 연구결과가 나온 이유는 선행연구에서 standard KPP운동과 one-handed KPP운동을 수행하면서 형성된 지지면 간의 크기가 큰 차이 없었기 때문이라고 보여진다. ${ }^{21}$ 반면 본 연구에 서는 각 운동을 수행하면서 형성된 지지면 간의 크기 변화가 선행연 구보다 컸기 때문에, 이와 같은 지지면의 요소가 아래등세모근의 근 활성도에 더 크게 기여한 것으로 보여진다. 선행연구에서는 대부분 네발기기 자세에서 하지의 움직임에 따른 어깨근육의 근활성도를 비 교했지만, ${ }^{21}$ 본 연구에서는 상지의 움직임에 따른 아래등세모근의 근 활성도를 비교했기 때문에 직접적으로 연구결과를 비교하기에는 한 계가 있다. 하지만 어깨 굽힘을 수행하면서 지지면의 변화가 아래등 세모근 근활성도에 영향을 미칠 수 있다는 것을 확인했기 때문에 임 상적 의의가 있다.

두 번째 이유는 열린 사슬 운동에서 어깨 굽힘 운동을 수행할 때 체중이 지지되는 지면의 불안정성이 아래등세모근 근활성도에 영향 을 미친 것이라 볼 수 있다. 불안정한 지면에 체중을 지지하고 어깨관 절 운동을 수행하게 되면 어깨 복합체의 근육 동원을 증가시킨다고 보고하였다.22-24 체중을 지지하는 지면이 근활성도에 미치는 영향을 확인해본 여러 선행연구에서 안정한 지면보다 불안정한 지면에 체중 을 지지한 운동이 몸통겉근육(trunk global muscles)을 활성화시켰으 며, ${ }^{25}$ 또 다른 선행연구에서는 닫힌 사슬 환경에서 푸쉬업 플러스 (push up plus) 운동을 수행할 때 하지가 딛고 있는 지면의 불안정성이 아래등세모근을 포함한 앞톱니근에 영향을 미쳤다. ${ }^{24}$ 이러한 결과와 비슷하게, 본 연구의 운동 중 SFP운동의 경우 안정적인 지면에서 체 중이 지지된 체 어깨관절의 열린 사슬 운동을 수행하였고, 지면의 불 안정성에 대한 영향을 적게 받았기 때문에 아래등세모근의 근활성 도가 낮은 것으로 보여진다. 반면 SFPUS, SFQPS운동의 경우 스위스 볼이라는 불안정한 지면에 체중 지지를 한 상태에서 어깨 굽힘 운동 을 수행하였기 때문에 관절을 안정화하기 위해 근육신경계 활동과 어깨복합체의 근육 동원이 촉진되어 아래등세모근의 근활성도가 SFP운동보다 높게 나온 것으로 보여진다. 추가적으로, SFP, SFPUS운 동을 수행하면서 지지면 위에 형성된 무게중심(center of gravity)은 비 교적 허리뼈 주변에 위치되었다. SFQPS운동은 좁아진 지지면으로 인 해 무게중심의 위치가 등뼈 주변에 형성되기 때문에 이런 요소들이 아래등세모근의 근육 기능을 더욱 활성화한 것으로 보여진다.

결론적으로 아래등세모근의 근활성도는 지지면이 좁고 불안정한 지면에 체중을 지지한 상태로 어깨 굽힘이 수행되었을 때 증가함을 확인할 수 있었다. 그러므로 SFQPS운동은 아래등세모근을 선택적 으로 활성화시키기 위해추천될 수 있다.

본 연구의 첫 번째 제한점은 실험에 참여한 대상자들이 모두 남성 이었기 때문에, 다른 성별에 일반화할 수 없다. 따라서 추후 연구에서 는 다양한 성별과 연령층의 대상자 조사가 필요하다. 두 번째 무게중
심을 측정하지 않았기 때문에 지지면 안에서 무게중심이 형성된 위 치를 정확히 확인할 수 없었다. 무게중심 위치에 따라 활성화되는 근 육이 변화하기 때문에 무게중심을 함께 확인하며, 운동을 수행하는 추가 연구가 필요하다. 세 번째 어깨 굽힘 시 간섭(crosstalk)으로 인해 서 동시 활성화되는 다른 어깨 근육의 근활성도를 확인하지 못했다. 어깨 굽힘 시 활성화되는 근육을 조사하여 근활성도를 확인하는 연 구가 필요하다. 마지막으로 본 연구는 근활성도의 변화를 단면 연구 로만 진행했기 때문에, 운동을 장시간 동안 수행하여 운동의 지속효 과를 확인하는 연구가 추가적으로 요구된다.

\section{ACKNOWLEDGEMENTS}

This research was funded by the university innovation support project of Hoseo University, grant number 221-01.

\section{REFERENCES}

1. Kerr A. Introductory biomechanics e-book. London, Churchill Livingstone, 2010:90-120.

2. Lehman GJ, MacMillan B, MacIntyre I et al. Shoulder muscle EMG activity during push up variations on and off a swiss ball. Dyn Med. 2006; 9(5):7.

3. Naughton J, Adams R, Maher C. Upper-body wobbleboard training effects on the post-dislocation shoulder. Phys Ther Sport. 2005;6(1):31-7.

4. Kendall FP, McCreary EK, Provance PG et al. Muscles: testing and function, with posture and pain. Philadelphia, Kippincott Williams \& Wilkins, 2005:329-31.

5. Cools AM, Declercq GA, Cambier DC et al. Trapezius activity and intramuscular balance during isokinetic exercise in overhead athletes with impingement symptoms. Scand J Med Sci Sports. 2007;17(1):25-33.

6. Ludewig PM, Reynolds JF. The association of scapular kinematics and glenohumeral joint pathologies. J Orthop Sports Phys Ther. 2009;39(2): 90-104.

7. Cleland J, Selleck B, Stowell T et al. Short-term effects of thoracic manipulation on lower trapezius muscle strength. J Man Manip Ther. 2004; 12(2):82-90.

8. Janda V. Muscles and motor control in cervicogenic disorders: assessment and management. In: Physical therapy of the cervical and thoracic spine, Edinburgh, Churchill Livingstone, 1994:195-215.

9. Lin JJ, Wu YT, Wang SF et al. Trapezius muscle imbalance in individuals suffering from frozen shoulder syndrome. Clin Rheumatol. 2005;24(6): 569-75.

10. Ebaugh DD, McClure PW, Karduna AR. Three-dimensional scapulothoracic motion during active and passive arm elevation. Clin Biomech. 2005;20(7):700-9.

11. McCabe RA, Orishimo KF, McHugh MP et al. Surface electromygraphic analysis of the lower trapezius muscle during exercises performed below ninety degrees of shoulder elevation in healthy subjects. N Am J Sports Phys Ther. 2007;2(1):34-43. 
12. Ekstrom RA, Donatelli RA, Soderberg GL. Surface electromyographic analysis of exercises for the trapezius and serratus anterior muscles. J Orthop Sports Phys Ther. 2003;33(5):247-58.

13. Wattanaprakornkul D, Halaki M, Boettcher C et al. A comprehensive analysis of muscle recruitment patterns during shoulder flexion: an electromyographic study. Clin Anat. 2011;24(5):619-26.

14. Moseley JB Jr, Jobe FW, Pink M et al. EMG analysis of the scapular muscles during a shoulder rehabilitation program. Am J Sports Med. 1992; 20(2):128-34.

15. Bagg SD, Forrest WJ. Electromyographic study of the scapular rotators during arm abduction in the scapular plane. Am J Phys Med. 1986;65 (3):111-24.

16. Lee WH, Ha SM, Park KN et al. A comparison of EMG activity for middle and lower trapezius muscle according to shoulder abduction angles. Phys Ther Kor. 2011;18(1):47-56.

17. Soderberg GL, Knutson LM. A guide for use and interpretation of kinesiologic electromyographic data. Phys Ther. 2000;80(5):485-98.

18. Ayotte NW, Stetts DM, Keenan G et al. Electromyographical analysis of selected lower extremity muscles during 5 unilateral weight-bearing exercises. J Orthop Sports Phys Ther. 2007;37(2):48-55.
19. Criswell E. Cram's introduction to surface electromyography. 2nd. Burlington, Jones \& Bartlett Publishers, 2010:293-7.

20. Sahrmann S. Movement system impairment syndromes of the extremities, cervical and thoracic spines e-book. St. Louis, Mosby, 2010:103-52.

21. Maenhout A, Van Praet K, Pizzi L et al. Electromyographic analysis of knee push up plus variations: what is the influence of the kinetic chain on scapular muscle activity? Br J Sports Med. 2010;44(14):1010-5.

22. de Oliveira AS, de Morais Carvalho M, de Brum DP. Activation of the shoulder and arm muscles during axial load exercises on a stable base of support and on a medicine ball. J Electromyogr Kinesiol. 2008;18(3): 472-9.

23. Lehman GJ, Gilas D, Patel U. An unstable support surface does not increase scapulothoracic stabilizing muscle activity during push up and push up plus exercises. Man Ther. 2008;13(6):500-6.

24. Yoon JG. Relationship between muscle activity and kinematic variables of the upper extremity during a push-up task on stable and unstable surfaces. J Kor Phys Ther. 2011;23(2):7-15.

25. Kim SH, Jeong SW, Park KN. Classification model to discriminate people with and without pain in the lower back and lower limb using symmetry data. J Musculoskelet Sci Technol. 2021; 5(2):72-9. 